\title{
Surgical repair of left-sided partial anomalous pulmonary venous connection associated with situs inversus totalis
}

\author{
Alwaleed Al-Dairy $^{1} \odot$ | Reem Shammout $^{2} \mid$ Raiean Al habbal $^{2}$
}

\author{
${ }^{1}$ Assistant Professor in Cardiac Surgery \\ at Faculty of Medicine, Damascus \\ University, Damascus, Syria \\ ${ }^{2}$ Faculty of Medicine, Damascus \\ University, Damascus, Syria

\section{Correspondence} \\ Alwaleed Al-Dairy, Cardiac Surgery \\ at College of Medicine, Damascus \\ University, and Cardiac Surgeon at \\ Damascus University Cardiac Surgery \\ Hospital, Damascus, Syria. \\ Email: alwaleedaldairy.aa@gmail.com
}

\begin{abstract}
The recognition of situs inversus is of great importance to avoid possible surgical mishaps that may result from the failure to recognize reversed anatomy or an atypical history. The repair of associated PAPVC with situs inversus totalis needs special attention during surgery due to the reversed anatomy.ss
\end{abstract}

\section{K E Y W O R D S}

congenital abnormalities, dextrocardia, partial anomalous pulmonary venous connection, situs inversus totalis

\section{1 | INTRODUCTION}

Situs inversus totalis is a rare congenital condition resulting from abnormal rotation of the cardiac tube during embryogenesis. Partial anomalous pulmonary venous connection is a rare heart defect that occurs when the pulmonary veins fail to connect normally during the development of the embryo. Herein, we describe the case a 30-month-old girl who presented with recurrent respiratory infections and dyspnea. Transthoracic echocardiography and computed tomography angiography revealed situs inversus totalis, partial anomalous pulmonary venous connection of left pulmonary veins, large atrial septal defect, and severe pulmonary hypertension. Surgical repair was performed with an excellent result. After a follow-up period of one year, the patient was asymptomatic with important clinical and radiological improvement.

Situs inversus is a rare congenital anomaly with an incidence of about 1 in 15000 of the general population. ${ }^{1}$ When associated with dextrocardia, it is known as situs inversus totalis (SIT) in which there is complete inversion (mirror-image) of the position of thoracic and abdominal viscera. This disorder may be isolated or associated with other cardiac defects (4\% of all SIT cases). ${ }^{2}$ Commonly, associated transposition of the great vessels is encountered. ${ }^{3,4}$ Partial anomalous pulmonary venous connection (PAPVC) is a rare congenital anomaly characterized by failure of normal connection of one or more of (but not all) the pulmonary veins to the left atrium. Alternatively, the anomalous pulmonary veins connect to the right atrium or one of its tributaries. ${ }^{5,6}$ The overall prevalence of PAPVC among general population has been reported to be between $0.4 \%$ and $0.7 \% .^{7}$ Its association with SIT is very rare. Herein, we report a rare case of SIT associated with PAPVC and secundum atrial septal defect (ASD) in a 30-month-old girl who underwent successful surgical repair.

\section{CASE PRESENTATION}

A 30-month-old female patient weighing 10800 grams, presented to our hospital with complaints of dyspnea and recurrent respiratory infections, and was diagnosed to have visceral situs inversus. She was the 3 rd of five siblings, born to non-consanguineous marriage couple, and she was delivered with no relevant birth details. Her siblings were normal. Clinical examination revealed systolic 
murmur in the base of the heart; the liver was clear on the left side. Chest $\mathrm{x}$-ray (CXR) showed dextrocardia with important cardiomegaly along with increased pulmonary

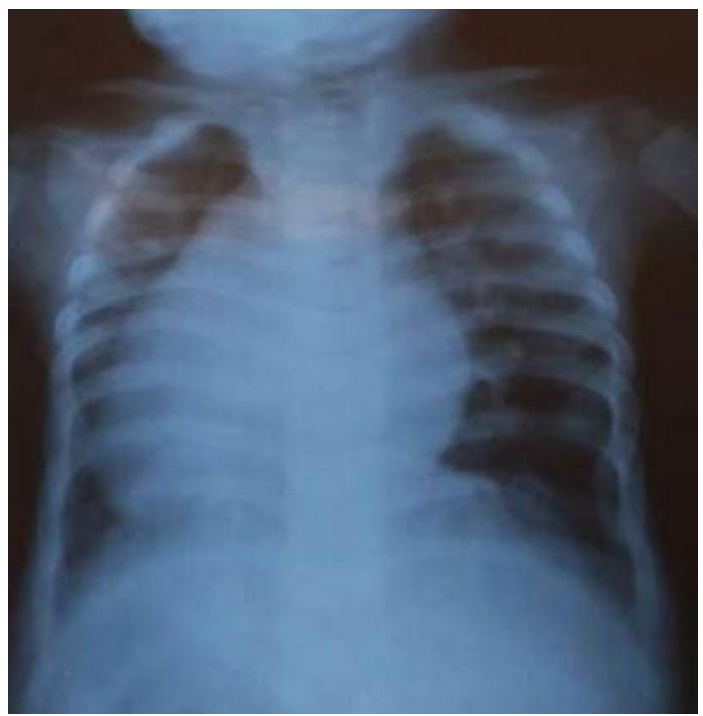

FI G URE 1 Chest x-ray showing dextrocardia with important cardiomegaly along with increased pulmonary vascular markings

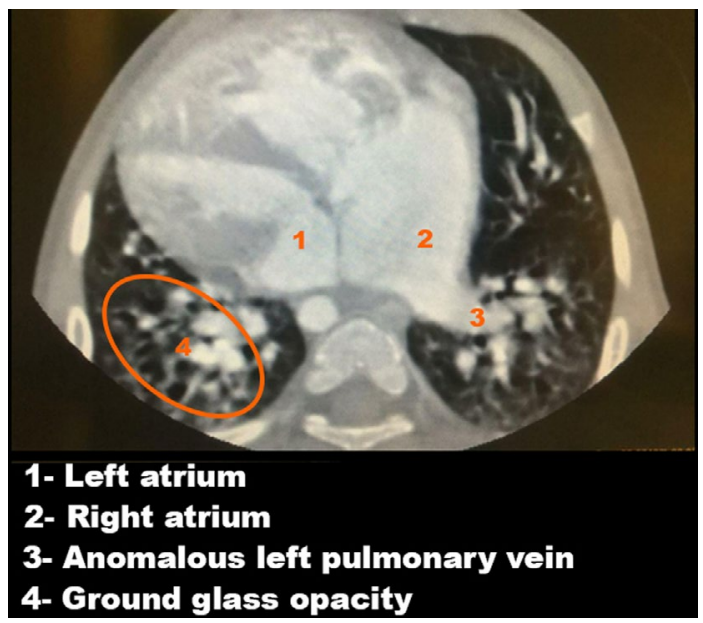

F I G U RE 2 Computed tomography angiography image showing the anomalous left pulmonary vein draining into the morphological right atrium vascular markings (Figure 1). Transthoracic echocardiography (TTE) confirmed the diagnosis of SIT along with large ASD measuring $8^{*} 12 \mathrm{~mm}$ with bidirectional flow across it, and a non-significant patent ductus arteriosus (PDA). There was severe right ventricular enlargement with mild-to-moderate tricuspid valve regurgitation. The left atrium cavity was small. Estimated systolic pressure in the right ventricle was $75 \mathrm{~mm} \mathrm{Hg}$ (calculated from the flow velocity of the tricuspid regurgitation jet and the assumed central venous pressure), and the mean pressure in the pulmonary artery was estimated to be $55 \mathrm{~mm} \mathrm{Hg}$. The right pulmonary veins were seen draining to the morphologically left atrium, but the left ones were not visible; therefore, computed tomography angiography (CTA) was requested. CTA revealed that the left pulmonary veins were draining anomalously to the left-sided right atrium with normal drainage of the right pulmonary veins to the left atrium (Figure 2). The patient was operated on through median sternotomy approach. The pericardium was opened. The morphological right atrium was to the left, and the apex of the heart was right-sided (Figure 3-A). Large PDA was seen on the right between the right pulmonary artery and the aorta. It was dissected and closed appropriately. A total cardiopulmonary bypass (CPB) was prepared. The aorta was clamped, and the heart was arrested by antegrade del Nido cardioplegic solution. The right atrium was opened with an incision parallel to the atrioventricular groove. The left pulmonary veins were seen draining directly to the right atrium just above the large ASD, whereas the right ones were draining to the left atrium. A large fresh autologous pericardial patch was fashioned to close the ASD and create a baffle draining the anomalous right pulmonary veins to the left atrium beneath the patch (Figure 3-B). The right atriotomy was closed, and the aortic cross clamp was released. The patient was weaned off the CPB uneventfully. Chest was closed in standard fashion. Mechanical ventilation was required for $8 \mathrm{~h}$. The patient's convalescence in the intensive care unit was uneventful. Postoperative TTE showed an excellent result of the operation with estimated systolic pressure in the right ventricle of about $35 \mathrm{~mm} \mathrm{Hg}$,
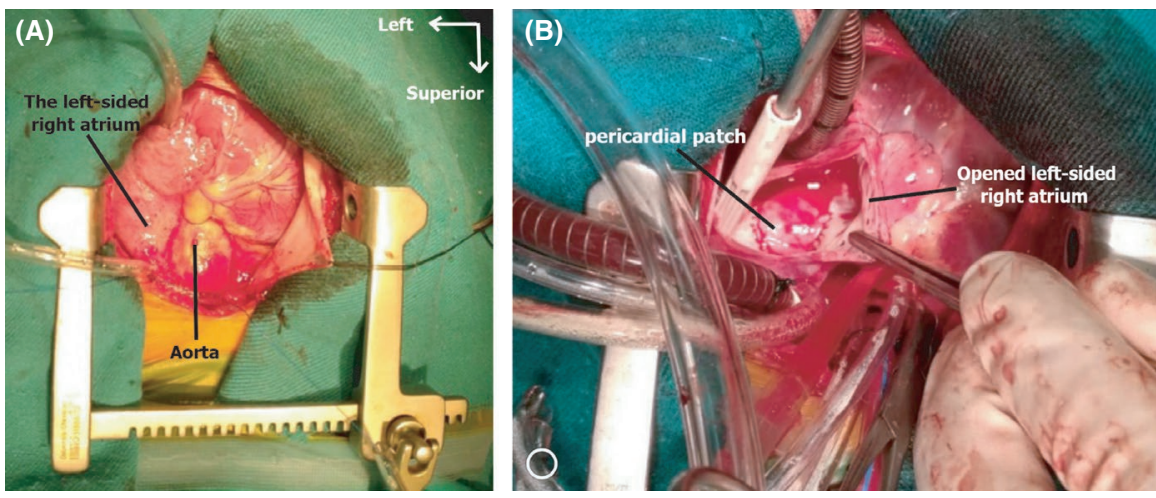

F I G U R E 3 (A) Intraoperative image showing the morphological right atrium to the left and the apex of the heart was right-sided. (B) Intraoperative image showing the sewn fresh autologous pericardial patch closing the ASD and creating a baffle draining the anomalous right pulmonary veins to the left atrium beneath the patch 
along with mild tricuspid regurgitation. The patient was discharged on the fifth day without any complications. The patient was followed up for 12 months, and she was without any complaints along with important clinical and radiological improvement.

\section{3 | DISCUSSION}

The incidence of cardiac anomalies in patients with SIT is about $4 \%$ (range from $0 \%$ to $10 \%$ ), and most commonly with transposition of the great vessels. ${ }^{1,3,4}$ The association of situs inversus totalis with PAPVC is very rare. ${ }^{8}$ Individuals with isolated SIT are often asymptomatic, and are usually diagnosed incidentally, or during routine tests. ${ }^{2,9,10}$ Therefore, the recognition of such rare anomaly is so important to prevent surgical mishaps such as when approaching appendicitis in a patient with SIT. ${ }^{9,10}$ When associated with SIT, clinical presentation of PAPVC will be the same as when it is an isolated lesion, and thus varies widely based on the degree of left to right shunt and other associated cardiac defects. ${ }^{11}$ The most encountered form of left-sided PAPVC is that in which the left upper pulmonary vein (or veins) drains via a vertical vein into the left innominate vein to further drain into the right atrium. ${ }^{11}$ In our patient, the left pulmonary veins were draining directly to the left-sided right atrium with normal drainage of the right pulmonary veins to the left atrium. Surgical repair is indicated for symptomatic PAPVC patients and asymptomatic individuals in whom Qp:Qs is more than 1.5 , or have an evidence of right ventricular dilation. ${ }^{11}$ In such circumstances, the surgeon should be aware of special aspects regarding the anatomy of cardiac chambers to avoid any pitfalls.

\section{CONCLUSION}

The recognition of situs inversus is crucial for preventing surgical mishaps that may result due to the oversight of reversed anatomy or an atypical history. The association of PAPVC with situs inversus totalis is extremely rare and should be approached like isolated PAPVC cases, with special attention for the reversed anatomy during surgery.

\section{CONFLICTS OF INTEREST}

The authors have no conflict of interest.

\section{AUTHOR CONTRIBUTIONS}

Alwaleed Al-Dairy planned and performed the work leading to the report; wrote and reviewed successive versions and participated in their revisions. Reem
Shammout participated in writing the report and approved the final version. Raiean Al habbal wrote and reviewed the successive versions and participated in their revisions.

\section{AUTHOR DECLARATION}

We declare that none of the authors listed on the manuscript is employed by a government agency that has a primary function other than research and/or education. Moreover, none of the authors is submitting this manuscript as an official representative or on behalf of the government.

\section{ETHICAL APPROVAL}

The manuscript was approved by ethics committee at Damascus University.

\section{CONSENT}

Written informed consent was obtained from the patient's parents for publication of this report and the images.

\section{DATA AVAILABILITY STATEMENT}

The data that support the findings of this study are available from the corresponding author, [A.A], upon reasonable request.

\section{ORCID}

Alwaleed Al-Dairy (D) https://orcid. org/0000-0002-2239-646X

\section{REFERENCES}

1. Madan Kumar K, Irineu Babu C, Chander S, Kumar A, Balchander J, Nachipaan M. Complete A-V canal defect with dextrocardia with CCTGA - a case report. IJTCVS. 2003;19:55.

2. Kumar A, Singh MK, Yadav N. Dextrocardia and asplenia in situs inversus totalis in a baby: a case report. J Med Case Reports. 2014;8:408.

3. Marta MJ, Falcão LM, Saavedra JA, Ravara L. A case of complete situs inversus. Rev Port Cardiol. 2003;22(1):91-104.

4. Ahadi R, Shamshirband H. Two case reports of situs inversus totalis. Anat Sci J. 2013;10(2):111-116.

5. Masrani A, McWilliams S, Bhalla S, Woodard PK. Anatomical associations and radiological characteristics of Scimitar syndrome on CT and MR. J Cardiovasc Comput Tomogr. 2018;12(4):286-289.

6. Li C, Teng P, Yang Y, Ni Y, Ma L. Partial anomalous pulmonary venous connection associated with hemoptysis: a case report. Medicine (Baltimore). 2019;98(23):e15893.

7. Yenigün BM, Kocaman G, Gürsoy Çoruh A, Akal RM. Partial anomalous pulmonary venous connection detected during right pneumonectomy. Interact Cardiovasc Thorac Surg. 2019;30(3):497-498.

8. Romano G, Guida G, De Garate E, Guida MC. Minimallyinvasive coronary surgery in dextrocardia and situs inversus totalis. Interact Cardiovasc Thorac Surg. 2010;11(6):820-821. 
9. Warren R, Hennessy OF. An unusual case of appendicitis. The American Journal of Surgery. 2010;199(6):e79-e81.

10. Gupta R, Soni V, Valse PD, Goyal RB, Gupta AK, Mathur P. Neonatal intestinal obstruction associated with situs inversus totalis: two case reports and a review of the literature. $J$ Med Case Rep. 2017;11(1):264.

11. Al-Dairy A, Al-Kyakhi L, Al-Mithiab L, Al-Bitar L, Nabhani MF. Surgical repair of an isolated left-sided partial anomalous pulmonary venous connection in an 18-month-old child. Gen Thorac Cardiovasc Surg. 2021;69(1):103-106. https://doi. org/10.1007/s11748-020-01401-7. Epub 2020 Jun 13 PMID: 32535817.

How to cite this article: Al-Dairy A, Shammout $\mathrm{R}, \mathrm{Al}$ habbal R. Surgical repair of left-sided partial anomalous pulmonary venous connection associated with situs inversus totalis. Clin Case Rep. 2021;9:e04914. https://doi.org/10.1002/ccr3.4914 